\title{
Effects of Constructivists' Learning Strategies on Senior Secondary School Students Achievement and Retention in Biology
}

\author{
Augustinah 'Nireti Duyilemi \\ Department of Science and Technical Education, Faculty of Education, Adekunle Ajasin University \\ Akungba, Akoko, Nigeria \\ Anaun Olubumi Bolajoko
}

4, Ademulegun Street, Polytechnic Road, Owo

\section{Doi:10.5901/mjss.2014.v5n27p627}

\section{Abstract}

\begin{abstract}
The study investigated the effects of constructivists' learning strategies on students' achievement and retention in Biology in selected Senior Secondary Schools in Owo Local government of Ondo State. The study adopted a pre-test, post-test, control, retention, quasi experimental design. A total of one hundred and sixty students from two co-educational schools participated in the study. 80 students served as experimental group while 80 served as the control group. Three research instruments were used for the study. These were Biology Achievement Test, teacher's instructional guide on: constructivists' strategies and instructional guide on conventional method. Two research questions and two null hypotheses were tested at 0.05 levels of significance. Analyses of data were carried out using Analysis of Covariance (ANCOVA) and Multiple Classification Analysis (MCA). The result obtained showed that there were significant main effects of treatment on students' achievement and retention in experimental group. Male students had higher achievement score than their female counterparts in the experimental group. The implication is that the constructivists' learning strategies should be emphasized more than the conventional method in order to enhance performance of students in Biology, students' learning and social relations relative to more traditional whole-class method of teaching.
\end{abstract}

\section{Introduction}

Human mental functions and accomplishments have their origins in social relationships and that knowledge is socially constructed through interactive effort to learn and solve problems (Okebukola, 1984; Ojo, 1989; Alebiosu, 1998; Yunyu, 1998; Esan, 1999; Adeyemi, 2002 and Akinbode, 2006 as quoted by Springer, Stanne and Donovan, 2007). They also noted that behavioural learning theory states that students will work hard on tasks from which they will secure some sort of reward and will fail on those tasks that provide no reward or yield punishment. Constructivists' strategies have been used for many years as a learning strategy in science. It is an approach to group work that maximizes the learning and satisfaction that result from working on a high performance team.

In relation to students taught conventionally or with teacher-centered lectures, constructively taught students tend to show higher academic achievement, greater persistence through graduation, better high level reasoning, critical thinking skills, deeper understanding of learned materials, greater time on task, less unruly behaviour in class, lower levels of anxiety, motivation to learn and achieve better and also, ability to view events from others.

\subsection{Background of the Study}

The level of scientific attainment of any nation is an important index for measuring its level of development. Opara as quoted by Ajewole (2006) opined every nation craves for science and technological, advancement which can be achieved through the medium of education. Science is a term used to describe organized knowledge that is based on observation and reasoning 2003). Man's enquiry of his environments lead to the study of science and other scientific related studies that provides answers to all questions, lead to wonderful discoveries and inventions that make life easier and gives us a better understanding about our existence. Science is better described as a key element of this modern world according to Meichtry (2003).

Biology is one of the science subjects taught in the secondary schools and research works discovered that 
students do hot perform well in external examinations like WAEC, NECO, NABTEB, because of the chalk and talk conventional method used mostly by teachers. The researcher used constructivists' learning strategy in order to improve students' performance in external examinations. Constructivists' strategy is a form of learning which is a term for various small groups in which students work together in order to maximize each other's learning (Johnson and Johnson, 1994; 1999). Numerous studies showed on constructivists' learning have shown the promotion of perspectives, positive and more supportive relationships with peers, positive attitudes towards subject areas and high self-respect or esteem are learnt.

It is a student-centered approach and a total shift from the teacher red conventional or traditional approach of teaching. The teacher is a facilitator in a constructivists' class where classroom activities are organized so that students can interact with and learn from each other as well as the teacher and the world around them. It is an arrangement in which students work in mixed ability groups and are rewarded on the basis of the success of the group as a whole (Stavin, 2000). The students therefore are able to learn more of what is taught and retain it longer than when the same content is presented in other instructional formats. Constructivists' learning has been found to improve students' performance (Hagen, 2000; Paulson, 1999), increase students' motivation (Paino, 2001), students' social skills and increase students satisfaction (Lord, 2001). Constructivists' strategy enables students to interact among themselves exchange ideas compete and make use of all the five senses. It is purely students centered and a total departure from the teacher-centered conventional method.

Therefore, it is very important to allow students to reflect their own ideas, prepare an environment giving them a chance to discuss their learning with other students and their teachers (Sagam and Millar, 2006). Teachers must do more than just teach the students a certain body of facts, they must direct students to have the ability to become increasingly self dependent, self directed and depend less on the teacher.

Conclusively, the main focus of these strategies is that by participating in constructivists' style, students are able to learn I concepts, processes and resented in material while working directly under the supervision of the classroom teacher who is the facilitator.

\subsection{Statement of the Problem}

The study of science instills in students' diligence, perseverance and observation with the learners. Biology education enables the learners to acquire problem-solving skills that provide ways of critical thinking and inquiring which help them to respond to widespread and changes in health, climate, technological development and advancement plus economic growth in the society where they live thereby improving the standard of living.

The teaching and learning of Biology which has over the decades yielded poor result has been attributed to the ineffective strategies adopted in the teaching of the subject which results into rote learning, parroting of unfamiliar ideas, regurgitation of facts, with the indication that such instruction strategies have not been adequate at improving students' achievement and retention.

Therefore, it is necessary to know the effects of constructivists' learning strategies on students' achievement and retention in Biology in the area of arthropods because it was discovered that students performed poorly in this aspect of Biology.

\subsection{Research Questions}

i. Are constructivists' strategies more effective than conventional method of teaching arthropods?

ii. Do males perform better than females when taught arthropods using constructivists' strategies?

\subsection{Research Hypotheses}

The following null hypotheses were tested at 0.05 level of significance:

i. There is no significant difference between the mean score of the students taught arthropods using the constructivists' strategies and those taught arthropods using conventional method.

ii. There is no significant difference between the mean scores of male and female students in Biology achievement test when taught arthropods using constructivists' strategies. 


\section{Design of the Study}

The study employed pre-test, treatment, post-test and retention quasi experimental factorial design $2 \times 2 \times 3$. Intact classes were used where students were randomly distributed into constructivists' and control groups.

\section{Population}

The population of the study consisted of all Senior Secondary School Class Two (SS2) biology students in Ondo State which are co-educational schools.

\section{Sample}

Two schools were randomly selected from the list of seventeen secondary schools in Owo Local Government Area of Ondo State purposively. A total number of one hundred and sixty biology students were selected for the study. The sample consisted of male and female students. Eighty students were assigned to the constructivists' method of instruction in the first school while another eighty students were assigned to the control group. Each school has two intact classes of 40 students each totaling one hundred and sixty students.

\section{Instrumentation}

There were research instruments designed and used by the researcher. These are:

1. Biology Achievement Test

2. Teacher's instructional guide on constructivist strategies

3. Teacher's instructional guide on conventional method.

The instruments were examined by experts in Biology and research supervisor that gave it a face and content validity. The instrument was trial tested by Kuder Richardson Formula KR 21 and a reliability coefficient of 0.6 was got.

\section{Procedure for Data Collection}

The researcher took permission from the principals of the schools before the field work. Biology teachers and the SS 2 students to be used for the study were identified in the two schools. The researcher trained participating teachers in the different schools. This training lasted for two weeks. This training helped the teachers involved to acquire necessary competence to carry out the work assigned them in order to achieve the best result in biology. After training, students for the study in the two groups were given pre-test by the researcher and the trained teachers at the beginning of the lesson from the questions contained in Biology Achievement Test (BAT) development by the researcher in order to have a feel for the existing knowledge on the lesson subjects. During this introductory assessment, a seed was planted for the eventual assimilation of new knowledge and its association with existing knowledge. Problems of the students were diagnosed and remedied and the result of the BAT was used, to split the students into two groups. The teachers taught their classes for six weeks for both the experimental and the control group. Six hours per week were used to cover the topic on Arthropods. After treatment, the post-test was administered. Retention test was carried out two weeks after the post-test. The data derived from the study were analyzed using descriptive statistics, Analysis of Covariance (ANCOVA) and Multiple Classification Analysis (MCA).

\section{Method of Data Analysis}

Descriptive Analysis was used to analyze the data collected for both experimental and retention tests while Analysis of Covariance (ANCOVA) and Multiple Classification Analysis (MCA) statistics were used to test the hypothesis at 0.05 level of significance.

\section{Data Presentation and Results}

Research Question 1: Are constructivists' strategies more effective than conventional method of teaching arthropods? 
Table 1: Descriptive analysis showing the achievement of biology students exposed to constructivists' strategies and conventional teaching methods

\begin{tabular}{|l|c|c|c|c|c|}
\hline Method & \multirow{2}{*}{} & \multicolumn{2}{|c|}{ Pre-test } & \multicolumn{2}{c|}{ Post-test } \\
\cline { 3 - 6 } & & Mean & S.D. & Mean & S.D. \\
\hline Constructivists' & 80 & 13.56 & 5.01 & 45.89 & 7.22 \\
\hline Conventional & 80 & 6.91 & 3.20 & 18.49 & 5.76 \\
\hline
\end{tabular}

Figure 1: Graph showing the achievement mean scores of students exposed to constructivists' strategies and conventional method in Biology

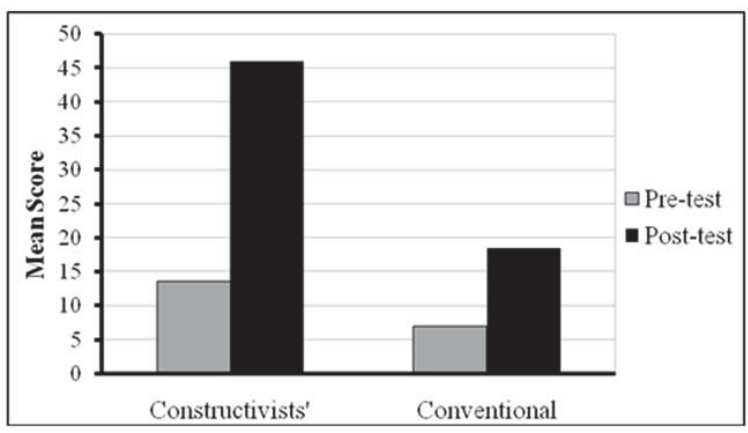

Table 1 and Figure 1 showed that the pre-test mean score of students exposed to constructivists' strategies is 13.56 while mean score for those in the conventional group is 6.91 . Their post-test scores are 45.89 and 18.49 respectively. It implies that constructivists' strategies constituted a better strategies for enhancing better achievement of students when taught arthropods in Biology than conventional teaching method.

Research Question 2: Do males perform better than females when taught arthropods?

Table 2: Descriptive analysis showing achievement mean scores of students

\begin{tabular}{|l|c|c|c|c|c|}
\hline Gender & \multirow{N}{*}{ N } & \multicolumn{2}{|c|}{ Pre-test } & \multicolumn{2}{c|}{ Post-test } \\
\cline { 3 - 6 } & & Mean & S.D. & Mean & S.D. \\
\hline Male & 43 & 14.63 & 5.15 & 45.33 & 7.85 \\
\hline Female & 37 & 12.32 & 4.60 & 46.54 & 6.45 \\
\hline
\end{tabular}

Fig 2: Graph showing achievement mean score of students taught arthropods using constructivists' strategies by gender

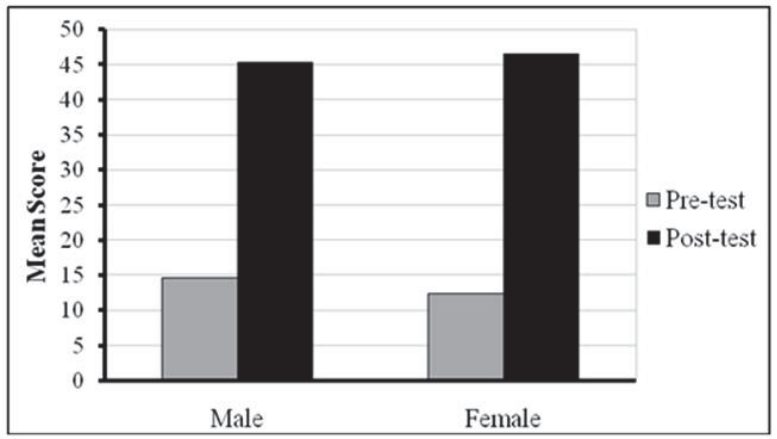

Table 2 and Figure 2 revealed that male students in the constructivists' group had a mean score of 14.63 in Biology before treatment while their female counterpart is 12.23. After exposure to constructivists' strategies, female students have higher mean score of 46.54 compared to male subjects with post mean score of 45.33 implying that female students performed better than their male counterparts when taught arthropods using constructivists' strategies. 


\subsection{Hypothesis 1}

There is no significant difference between the mean scores of the students taught arthropods using the constructivists' method and those taught arthropods using conventional method.

Table 3: ANCOVA showing the achievement mean scores of students in the constructivists' and conventional groups

\begin{tabular}{|l|c|c|c|c|c|}
\hline Source & SS & Df & MS & F-cal & F-table \\
\hline Corrected model & 31129.572 & 2 & 15564.786 & 433.521 & 3.04 \\
\hline Covariance (pre-test) & 1099.172 & 1 & 1099.172 & 30.615 & 89.00 \\
\hline Groups & 13216.386 & 1 & 13216.386 & 368.112 & 3.89 \\
\hline & 5636.803 & 157 & 35.903 & & \\
\hline Corrected total & 36766.375 & 159 & & & \\
\hline Total & 202532.000 & 160 & & & \\
\hline
\end{tabular}

Table 3 showed F-cal (368.112) is greater than F-table (3.89) at 0.05 level of significance. The null hypothesis was rejected, therefore there is significance difference between the mean scores of students taught arthropods using constructivists' strategies and those taught using conventional method. To determine the effect of the treatment on mean scores of students Multiple Classification Analysis (MCA) was used. The result is presented in Table 4.

Table 4: Multiple Classification Analysis showing the effect of treatment on students' achievement in Biology

\begin{tabular}{|l|c|c|c|c|c|}
\hline \multicolumn{7}{|c|}{ Grand Mean = 32.19 } \\
\hline Variable + Category & N & Unadjusted Devn & Eta & Adjusted for independent covariance & Beta \\
\hline Constructivists' & 80 & 13.70 & & 7.12 & \\
\hline Conventional & 80 & -13.70 & 1.98 & -7.10 & \\
\hline Multiple R & & & & & .698 \\
\hline Multiple R & & &. & .487 \\
& & & & $1 \_\mathrm{J}$ \\
\hline
\end{tabular}

Table 4 showed that students exposed to constructivists' strategies had higher adjusted mean score of 39.31 compared to their counterparts in the conventional group with an adjusted mean score of 25.09 implying that constructivists' enhances students achievement in Biology.

\subsection{Hypothesis 2}

There is no significant difference between the mean score of male and female students in Biology achievement test when taught arthropods using constructivists' strategies.

Table 5: ANCOVA summary of students' achievement scores of constructivists' group by gender

\begin{tabular}{|l|c|c|c|c|c|}
\hline Source & $\mathbf{8} \%$ & Df & MS & F-cal & F-table \\
\hline Corrected model & 1012.304 & 2 & 506.152 & 12.656 & 307 \\
\hline Covariance (pre-test) & 982.948 & 1 & 982.948 & 24.402 & 3.92 \\
\hline Sex & 156.337 & 1 & 156.337 & 3.881 & 3.92 \\
\hline Error & 3101.683 & 77 & 40.282 & & \\
\hline Corrected total & 4113.988 & 79 & & & \\
\hline Total & 172567.000 & 80 & & & \\
\hline
\end{tabular}

Table 5 showed that F-cal (3.88) is less than F-table (3.92) at 0.05 level of significance. The null hypothesis is not rejected. 
Table 6: ANCOVA showing retention mean scores of students in constructivists' group by ability level

\begin{tabular}{|l|c|c|c|c|c|}
\hline Source & SS & Df & MS & F-cal & F-table \\
\hline Corrected model & 128.227 & 2 & 64.114 & 1.744 & 3.07 \\
\hline Covariate (pre-test) & 92.219 & 1 & 92.219 & 2.509 & 3.92 \\
\hline Ability level & 126.473 & 1 & 126.473 & 3.440 & 3.92 \\
\hline Error & 2830.573 & 77 & 36.761 & & \\
\hline Corrected total & 2958.800 & 79 & & & \\
\hline Total & 292882.000 & 80 & & & \\
\hline
\end{tabular}

$P>0.05$

Table 6 showed that F-cal (3.440) is less than F-table (3.92) at 0.05 level of significance. The null hypothesis is accepted. Therefore, there is no significant difference in the mean scores of the high, medium and low scorers in the retention test when taught arthropods using-constructivists' strategies.

Table 7: ANCOVA summary of treatment and ability on retention

\begin{tabular}{|l|c|c|c|c|c|}
\hline \multicolumn{7}{|c|}{ Mean scores of students in Biology } \\
\hline Source & SS & Df & MS & F-cal & F-table \\
\hline Corrected model & 29537.935 & 5 & 5907.587 & 165.387 & 2.26 \\
\hline Covariate (pre-test) & 364.074 & & 364.014 & 10.193 & 3.89 \\
\hline Group & 1997.358 & 1 & 1997.358 & 55.917 & 3.89 \\
\hline Ability level & 51.666 & 2 & 25.833 & 0.723 & 3.04 \\
\hline Group* Ability level & 22.168 & 1 & 22.168 & 0.621 & 3.89 \\
\hline Error & 5500.840 & 154 & 35.720 & & \\
\hline Corrected total & 35038.775 & 159 & & & \\
\hline Total & 384168.000 & 160 & & & \\
\hline
\end{tabular}

$\mathrm{P}>0.05$

Table 7 shows that F-cal (.621) is less than F-table (3.89) at 0.05 level of significance. The null hypothesis is accepted. Therefore, there is no significance effect of constructivists' strategies and the conventional method and scoring levels of students on the retention mean scores of students. Similarly, the main effect of scoring level on retention mean scores is not significant at 0.05 level $(F=0.723, P>0.05)$. However, treatment has significant on retention mean scores of subjected $(F=55.917, P<0.05)$.

Teachers should therefore improve their instructional approach because it can easily be manipulated to bring positive changes in learners than other factors like ability and intelligence. According to Olulonyo (2010), teachers should improve their teaching methods in order to enhance better understanding among students so that their interests could be aroused.

The constructivists' strategies were found to be more effective than the conventional methods with regard to achievement and retention in biology in the area of arthropods. This conforms with Duyilemi (2005) who found that students taught pollution in Biology with constructivists strategy performed better than those taught using conventional method. Constructivists' strategies lead students to know that acquiring real knowledge is better than rote learning that can be easily forgotten. It helps students to contribute their own idea to learning and this shows that their minds are not totally empty and vacant.

From the results obtained, male students performed better than female students taught using the constructivists' strategy though the difference was not significant. This conforms with Ezirim et. al. (2006) who observed that gender ficant influence on science.

The findings of the research call for more innovations by science teachers because of the importance of science especially Biology to humanity. Science teachers should be ready to adopt modern strategies of teaching in Nigerian secondary schools.

In addition, constructivist strategies help to instill confidence in the students and remove the fear of poor performance. However other teaching methods should also be added in order to improve teaching and learning processes in Nigerian secondary schools. 


\section{References}

Adeyemi, S.B. (2002). Relative Effects of Cooperative and Individualistic Learning Strategies on Students' Declaration and Procedural Knowledge in Map work in Osun State, Nigeria. Ph.D. Thesis, Department of Teacher Education, University of Ibadan, Ibadan.

Ajewole, G.A. (2006). Promoting the Understanding of Science, Technology Mathematics (STM) Education in Nigeria for the Future. Akoko Journal of Pure and Applied Science Education.

Akinbode, M.B. (2006). The Relatives Effect of Two Instructional Strategies Learning Outcomes in Islamic Studies. Ph.D. Thesis, Institute of Education, University of Ibadan, Ibadan.

Alebiosu, K.A. (1998). Effects of Two Cooperative Learning Models on Senior Secondary School Student, Learning Outcomes in Chemistry, Ph.D. Thesis, Department of Teacher Education, University of Ibadan, Ibadan.

Duyilemi, A.N (2005): Engendering Science and Mathematics Education in Nigeria through Constructivist Intervention Strategies. Proceedings of the Interventional Conference on Education, National University of Singapore.

Esan, A.O. (1999): Effect of Cooperative and Individualist Problem Solving Strategies on Students Learning Outcomes in Secondary School Mathematics. Ph.D. Thesis, Department of Teacher Education, University of Ibadan, Ibadan.

Ezirim, M.U. (2006): Scaling up girls participating in science Education; Towards a score card on quality education. E. Okeke and M. Opara (Eds) Science Teachers' Association of Nigeria. Gender and STM education series (I)

Hagen, J.P. (2000): "Cooperative Learning in Organic II: Increased Retention on a Commuter Campus" Journal of Chemistry Education (77), Pp 1441-1444.

Johnson, D.W. and Johnson, R.T. (1994): Learning Together and Alone. Cooperative, Competitive and Individualistic Learning (4th edition) Boston MlynandBacoa

Johnson, D.W. and Johnson R.I. (1999): Making Cooperative Learning Wort. Theory into Practice, 36, 2 67-73

Lord, T.R. (2001) "101 Reasons for using cooperative learning in Biology teaching". The American Biology Teacher (63), Pp 30-38.

Meichtry, Y.J. (2003): The Nature of Science and Scientific knowledge. Implication for Designing a Pre-service Elementary Methods Course

Ojo, O.M. (1989): The Differential Effectiveness of Cooperative, Competitive and Individualistic Goal Structures on Students' Performance in Chemistry. Ph.D. Thesis, Department of Teacher Education, University of Ibadan, Ibadan.

P.A.O. (1984): Effects of Cooperative, Competitive and Individualistic Laboratory International Patterns on Students Performance in Biology. Ph.D. Thesis, Department of Teacher Education University of Ibadan, Ibadan.

Omolade, Z.A. (2003): General Studies Education (for Students in Tertiary Institutions) ljebu-ode, Lucky Odoni (Nig) Enterprises

Paino, P. (2001): "Games Students Play" The Science Teacher (68) 4, Pp28-30.

Paulson, D.R. (1999): "Active Learning and Cooperative Learning in Chemistry Education" (76), Pp 1136 - 1140.

Sagam, M. and Millar, R. (2006): Upper Higher School Students' Understanding of Electromagnets m. international journal of science - cation 2c, 543-566;

Springer, L. Stanne, M.E. and Donavan, S. (2007): Effects of Small Group Learning on Undergraduates on Science, Mathematics, Engineering and Technology. A Meta- analysis. National Institute for science Education, Maidson Wl, 1997 http://www. wcerwisc.edu/nise/cll/resource/r2.htm

Slavin, R.E. (2002): Educational Psychology Theory and Practice. Boston: Allyn and Bacon

Yunyu, Y. (1998): The Effects of Cooperation with Inter-Group Competition on Performance and Attitude in a Computer Assisted Science Instruction. Journal of Computer in Mathematics and Science Teaching (17) 4, Pp 381-395. 